\title{
BLAMBANGAN PEOPLE'S RESISTANCE TO VOC YEAR 1767-1773
}

\section{PERLAWANAN RAKYAT BLAMBANGAN TERHADAP VOC TAHUN 1767-1773}

\author{
Ahmad Ferdi Abdullah \\ Guru SMP Darul Qur'an Bumiharjo Glenmore \\ darqu.oke@gmail.com
}

(*) Corresponding Author

+62 813-3370-0507

How to Cite: ferdi (2019). Title of article. Santhet, 3(2), 46- 55

doi

$\begin{array}{ll}\text { Received: } & \text { 21Juni } 2019 \\ \text { Revised : } & 28 \text { September } 2019 \\ \text { Accepted: } & \text { 19 Oktober2019 } \\ \text { Keywords: } & \text { Rakyat; } \\ & \text { Blambangan; } \\ & \text { VOC; }\end{array}$

\begin{abstract}
This research is motivated to find out the extent of Blambangan people's struggle in dealing with voc using a qualitative research approach to the study of literature and interviews. the results of the study showed that the Blambangan kingdom suffered the consequences VOC power which tortures the people through its monopil, this is the cause of people's resistance. To be able to answer that problem, this study aims to describe the resistance of the people of Blambangan against the VOC in 17671773 . Specifically, this study aims to find out (1) the people of Blambangan make a fight against the VOC. (2) the factors that caused the people of Blambangan to resist the VOC. (3) the impact of resistance to the VOC in Blambangan. To achieve these research objectives, the research method that I use is a type of historical research with data collection techniques through library research sourced from books, documentation and observations. Meanwhile, to analyze the data the authors used source criticism techniques both externally and internally, after that the authors conducted the analysis. From the results of this analysis the authors reference in answering the problems in this study. The results of the study showed that the Blambangan Rakyat Resistance was led by two great figures of his time, who had many followers, namely Wong Agung Willis and Mas Rempeg (Jagapati). Agung Willis's position in Blambangan became stronger when Mas Anom and Mas Weka, two Blambangan regents appointed by the Company decided to join him, the Dutch expected Blambangan to increase because ethnic Chinese and Bugis joined him, with this power the resistance succeeded in winning even though in the end Agung Willis was captured and Mas Rempeg was injured and later died.
\end{abstract}

\section{PENDAHULUAN}

Sejarah pasti dimiliki oleh setiap daerah tidak terkecuali di Indonesia, di Indonesia sendiri terdapat beragam sejarah yang menjadikan indonesia memiliki banyak suku bangsa. Namun, pada era ini sudah sangat sulit menemukan orang yang masih mengetahui tentang sejarah dikarenakan kurang menariknya sejarah Indonesia masa lalu yang berakibat banyaknya sejarah asing yang cenderung lebih menarik seperti sejarah peradaban Yunani dan Peradaban Persia sehingga menggeser keberadaan sejarah yang ada. Meskipun demikian, sejarah di Indonesia memiliki potensi yang luar biasa dan harus digali dan diteliti oleh generasi muda di indonesia supaya bangsa kita kedepanya bisa mencintai sejarah bangsanya sendiri karena kita sebenarnya kaya akan sejarah terutama banyaknya sejarah- sejarah lokal disetiap daerah di Indonesia.

Pada masa kini, sejarah akan dapat dipahami oleh generasi penerus dari masyarakat yang terdahulu sebagai suatu cermin untuk menuju kemajuan dalam kehidupan bermasyarakat, berbangsa, dan 
bernegara. Peristiwa yang terjadi pada masa lampau akan memberi kita gambaran tentang kehidupan manusia dan kebudayaannya di masa lampau sehingga dapat merumuskan hubungan sebab akibat mengapa suatu peristiwa dapat terjadi dalam kehidupan tersebut, walaupun belum tentu setiap peristiwa atau kejadian akan tercatat dalam sejarah.

Selain sejarah nasional yang kita kenal sekarang ini, telah berkembang pula istilah baru dalam ilmu sejarah, yakni sejarah lokal. Studi sejarah lokal ini terkait erat dengan tradisi lisan dan tertulis di masyarakat. Sejarah yang kita miliki bermula berasal dan sejarah lokal. Babad, tambo, hikayat dan sebagainya yang menceritakan asal usul suatu daerah tertentu, sebetulnya sudah merupakan tradisi penulisan sejarah daerah tertentu, dari sejarah lokal ini penulis ingin meneliti tentang sejarah lokal yang ada di kerajaan Blambangan yang sekarang bernama Banyuwangi. Banyuwangi, kabupaten ujung timur pulau Jawa, tak bisa dipisahkan dengan nama Blambangan. Karena secara historis di Banyuwangilah kekuasaan kerajaan Blambangan terakhir berada. Sebuah kerajaan yang sering luput dari perhatian para ahli sejarah. Lebih kuat kesanya sebagai dongeng dari pada kenyataan sejarah. Padahal Blambangan memiliki peranan yang berarti dalam percaturan politik sosial budaya di Jawa dan Bali pada khususnya. Sering tidak disadari bahwa kerajaan Blambangan adalah kerajaan yang semasa kerajaan Majapahit bahkan dua abad lebih panjang umurnya. Blambangan adalah kerajaan yang paling gigih bertahan terhadap serangan Mataram dan VOC serta Blambanganlah kerajaan yang paling akhir ditaklukkan penjajah Belanda di Pulau Jawa. Akibat peperangan yang tiada henti baik dengan Mataram, Bali maupun Belanda menyebabkan tanah Blambangan kehilangan penduduk dalam jumlah besar, baik meninggal karena peperangan maupun sebagai tawanan perang, sedemikian rupa hingga kejayaan di masa lampau terlupakan (Winarsih, 1995:12).
Kedatangan Belanda ke Ujung Timur Jawa diawali oleh ketidak merataan populasi penduduk di pulau Jawa. Hal ini dapat dilihat dari jumlah penduduk yang padat di daerah Jawa bagian barat sementara di daerah Jawa bagian timur jumlah penduduknya sangat sedikit. Penyebaran penduduk yang tidak merata tersebutsalah satunya disebabkan oleh sikap Belanda yang tidak ramah sehingga sering mendapat perlawanan dari penduduk setempat. Kemudian muncullah gagasan untuk melakukan penguasaan terhadap daerah Timur Pulau Jawa yaitu Blambangan yang pada abad 18 merupakan wilayah kekuasaan Mataram. Belanda tidak dengan mudah menguasai daerah timur Jawa, karena pada pertengahan abad 18 Inggris juga mulai melirik kawasan timur Jawa dalam rangka ingin mencari komoditas bagi perdagangan Inggris (Margana, 2012:2)

Masyarakat Banyuwangi yang dalam konteks kesejarahan dikenal dengan masyarakat Blambangan, memiliki banyak tokoh local yang tercatat berjuang dan berkorban melawan penjajah VOC dan Hindia Belanda. Salah satu tokoh local yang eksist berjuang melawan VOC dan Belanda adalah Pangeran Wilis atau dikenal Wong Agung Wilis.

Mempelajari tokoh local sejarah seringkali menjadi pelajaran yang tidak menarik bagi sebagian generasi muda sekarang. Mengetahui perjuangan tokoh local daerah dianggap tidak memiliki peranan penting bagi masa depan generasi muda sekarang. Sering kali tokoh local hanya menjadi obrolan dikalangan orang tua saja, generasi muda lebih senang membicarakan tokoh-tokoh superhero yang berasal dari luar negeri dibandingkan membicarakan tokoh local daerah yang telah berkorban dan berjasa di daerahnya.

Untuk membangun daerah diperlukan sumber daya alam dan sumber daya manusia. Sumber daya alam diperoleh dari kekayaan alam sedangkan sumber daya manusia diperoleh dari kekayaan nilai-nilai dan karakter unggul yang dapat dijadikan sebagai modal untuk membangun daerahnya. Salah satu nilai dan karakter 
yang dibutuhkan sebagai modal pembangunan adalah nilai dan karakter kepahlawanan.

Kurangnya pengetahuan terhadap nilai-nilai kepahlawanan tokoh local ini, menyebabkan hilangnya nilai-nilai keteladanan yang dapat dicontoh dari para pahlawan kita sendiri. Tidak adanya nilainilai keteladanan ini menyebabkan lunturnya nilai cinta tanah air (patriotisme) dan hilangnya nilai kebangsaan (nasionalisme) dikalangan generasi muda.

Kerajaan Blambangan merupakan kerajaan Hindu terakhir di Jawa. Kerajaan ini lahir pada 1295, dua tahun setelah Majapahit berdiri. Raja Majapahit Raden Wijaya memberikan "Istana Timur" ini kepada Arya Wiraraja (Adipati Sumenep) dengan ibu kota di Lumajang karena ia telah membantu perjuangan mendirikan Majapahit. Setelah keruntuhan Majapahit pada abad ke-15, Kerajaan Blambangan mampu bertahan hingga abad ke-18. Namun riwayat Kerajaan Blambangan tak pernah disebut dalam sejarah nasional Indonesia. Selama ini, masih sedikit sejarawan yang meneliti Blambangan. Peninggalannya pun bisa dihitung dengan jari. Riwayat kerajaan ini mayoritas berupa cerita rakyat yang kental dengan legenda atau mitos, seperti kisah DamarwulanMenakjingga, yang kerap dibawakan dalam seni pertunjukan.

Setiap daerah pasti memiliki tokoh local sejarah. Masyarakat Indonesia yang dijajah oleh Asing hampir 3 abad lamanya, melahirnya tokoh-tokoh local daerah yang berjuang dan mengorbankan dirinya untuk melawan penjajah demi mempertahankan kepentingan daerahnya, seperti Pangeran Wong Agung Willis dan Rempeg Jagapati, Para tokoh inilah yang memberontak terhatap VOC.Masyarakat Banyuwangi yang dalam konteks kesejarahan dikenal dengan masyarakat Blambangan, memiliki banyak tokoh local yang tercatat berjuang dan berkorban melawan penjajah VOC dan Hindia Belanda.

Dalam penelitian ini Penulis perlu adanya pembatasan, baik menyangkut waktu, tempat maupun fokus atau inti permasalahan yang diteliti. Lingkup temporal penelitian ini adalah mulai tahun 1767 sampai tahun1773. Tahun 1767 dijadikan batas awal karena pada tahun ini adalah awal terjadinya Perlawanan yang dipimpin oleh Agung Willis. Sedangkan tahun 1773 dijadikan sebagai batas akhir karena Perlawanan di Blambangan berakhir pada tahun itu.

Berdasarkan latar belakang di atas penulis tertarik untuk mengkaji dan menganalisis mengenai terjadinya Perlawanan Rakyat dengan dipimpin oleh Agung Willis Dan Rempeg Jagapati yang penulis rumuskan dalam judul "Perlawanan Rakyat Blambangan Terhadap VOC Tahun 1767-1773"

\section{METODE PENELITIAN}

Metode merupakan cara yang paling efektif dan efisien dalam melakukan penelitian sesuai dengan masalah yang dikaji. Metode yang digunakan dalam penulisan skripsi ini adalah metode historis. Metode historis adalah proses menguji dan menganalisa secara kritis rekaman dan peninggalan masa lampau dan hasilnya berupa rekonstruksi imajinatif atau historiografi (Gottschalk, 1986:32). Langkahlangkah dalam penelitian sejarah menurut Ismaun (2005: 34) terdiri dari empat tahap, yaitu sebagai berikut.

Pertama Heuristik, yaitu pencarian dan pengumpulan sumber sejarah yang relevan untuk mendapatkan data-data atau materi sejarah, atau evidensi sejarah yang berhubungan dengan permasalahan yang akan dikaji oleh peneliti (Ismaun, 2005; Sjamsuddin, 2007). Dalam hal ini penulis melakukan pencarian sumber kemudian mengumpulkan sumber-sumber yang diperlukan untuk bahan penelitian.

Kedua Kritik, yaitu usaha menilai sumbersumber sejarah. Semua sumber dipilih melalui kritik eksternal dan internal sehingga diperoleh fakta yang sesuai dengan permasalahan penelitian (Ismaun, 2005:50). Dengan kritik eksternal diharapkan hasil penelitian sejarah teruji dari sisi keaslian data yang digunakannya. Sedangkan dengan kritik internal, diharapkan kasil penelitian sejarah teruji kebenaran, keakuratan dan kerelevanan 
data tersebut untuk ditafsirkan dan dijelaskan. Kritik sumber ada dua macam, yaitu:

a) Kritik ekstern atau kritik luar memiliki fungsi untuk menilai otensitas sumber sejarah. Sumber otentik tidak mesti harus sama dengan sumber dan isi tulisan dalam dokumen harus sembunyi dan sama dengan sumber aslinya,baik menurut isinya yang tersurat maupun tersirat.

b) Kritik intern atau kritik dalam memiliki fungsi untuk menilai kredibilitas sumber dengan mempersoalkan isinya, kemampuan pembuatannya, tanggung jawab dan moralnya. Untuk menguji kredibilitas sumber (sejauh mana bisa dipercaya) diadakan penilaian instrinsik terhadap sumber dengan mempersoalkan hal- hal tersebut. Kemudian dipunguti fakta-fakta sejarah melalui perumusan data yang didapat, setelah diadakan penelitian terhadap evidensi-evidensi dalam sumber.

Ketiga Interpretasi atau penafsiran merupakan usaha memahami dan mencari hubungan antar fakta sejarah sehingga menjadi satu kesatuan yang utuh dan rasional.

Pada tahap ini penulis melakukan penafsiran terhadap fakta-fakta dan data dengan konsep dan teori yang telah diteliti oleh penulis sebelumnya. Fakta dan data tersebut kemudian dihubungkan dengan konsep yang berhubungan dengan permasalahan yang dikaji.

Empat Historiografi adalah usaha untuk mensintesiskan data- data dan fakta fakta sejarah menjadi suatu kisah yang jelas atau suatu penulisan yang utuh, baik itu berupa karya besar ataupun hanya berupa makalah kecil (Ismaun, 2005; Sjamsuddin, 2007). Historiografi merupakan tahap terakhir dalam sebuah penelitian sejarah.

\section{HASIL DAN PEMBAHASAN}

\section{Kerajaan Blambangan Periode Awal}

Kekayaan dan kesuburan tanah Blambangan telah diketahui oleh Belanda
Jauh sebelum bangsa tersebut menginjakkan kakinya di Indonesia. Oleh sebab itu, Belanda ingin secepatnya menguasai Blambangan. Tetapi keinginan Belanda itu terkendala oleh pelbagi faktor seperti: blambngan merupakan daerah yang jauh dari pusat pemerintahan di indonesia, begitu pula terjalinya hubungan yang erat melalui ikatan perkawinan politik antara Blambangan dan Bali telah menunjukkan betapa kokohnya pasukan Blambangan (Soetrisno, 1976:85).

Sebelum Belanda Berpengaruh di daerah Blambangan,Inggris sudah terlebih dahulu melakukan hubungan dagang dengan para penguasa blambangan. Diperkirakan kedatangan para pedagang Inggris terjadi pada masa sekitar pemerintahan Danuningrat. Bagi orang Inggris, Blambangan sangat terkenal hasil pertanian seperti: cengkeh, pala, dan tembakau. Mereka menawarkan barang dagangan seperti: mesiu, peluru, senapan, dan kain sutra. Kedatangan para saudagar inggris diterima dengan sangat baik oleh penguasa Blambangan, secara otomatis juga penguasa Bali. Sudagar Inggris itu menghendaki hak monopoli perdagangan untuk memborong semua hasil bumi Blambangan. (Samsubur, 2006:128)

\section{Perlawanan Rakyat Dalam Pimpinan Wong Agung Willis}

Sekarang kita kembali ke negara Blambangan. Segenap rakyat kecil telah duduk dihadapan petugas VOC. Penguasa VOC merasa senang, karena telah ditaati segala perintahnya. Orang-orang Blambangan dikenai kewajiban menyediakan tenaga 50 orang setiap hari nya. Mereka itu, pagi/sore masuk ke loji bekerja setiap hari. Selain itu rakyat juga sering harus menyuguhkan kerbau atau sapi kepada VOC bahkan tak ada senggangnya. Walau demikian masih juga ada kesedihan yang ditanggung komando VOC, yaitu masalah penyakit.

Wang Agung Wilis, Gusti Agung Dalem Dimade menggerakkan prajuritnya. Segenap punggawanya dipanggil, demikian pula para putrinya untuk berkumpul. Menurut 
Mas Purwasastra, orang- orangnya itu adalah Ki Surantani, Gajahnasar, Ki Tambagan, Pasekan, Ki Tambaayu dan Gajah-ailingan. Raja mernerintahkan, agar Ki Tambakbayu mengundangkan, membuat beteng yang kokoh, di bahwa rakyat dan Pasukan Munguwi segera membuat benteng yang kokoh disepanjang pantai Seseh setebal 23 batang tombak. Setiap jurang yang sepanjang merapat pasanglah meriam yang banyak. Di padang luas di pantai dilarang didirikan beteng, karen dipesiapkan untuk berperang. Raja itu menjelaskan, bahwasanya raja Jawa (Mataram) mau rnenyerang Bali juga karena hasutan Kumpeni Belanda. VOC inilah yang dimintai bantuan Pangeran Jingga sehingga Blambangan dikuasai VOC. Karena itu tak kekelirulah bila Pangeran Danuningrat itu segera dihukum mati di Seseh. Dialah penyebab Blambangan celaka itu.

Para mantrinya ditanya, bagaimana jika Bali berperang lawan Kumpeni Belanda? Bagaimana jika VOC itu dibujuk dengan pemberian wanita cantik? Hal ini demi menyelamatkan rakyat, keseluruhannya. Bagaimanakan pikir kalian? Kemudian $\mathrm{Ki}$ Tambakbayulah yang memebri jawaban, bahwa rencana rajanya itu tepat. Jika pemberian wanita cantik ditolak, maka sebaiknya kita lawan perang saja. Bila negara Bali serba cukup, maka segera mendirikan beteng agar tidak telambat. Karena itu maka raja di Bali itu segera mengundangkan bahwa para parjurit, punggawa dan mantri siang malam . wajib membangun beteng setebal 3 depa $=2$ batang tombak.

Dalam bulan Pebruari 1768 oleh VOC Pangeran Wilis dituntut untuk melaporkan dirinya di Beteng Banyualit dan bertolak ke Surabaya, sampai 2 kali beliau menolaknya. (C. Leckerker, 1923 : 1052.) Kemudian pada 01 Maret 1768 Komandan VOC di Blambangan, Adrianus Van Rijke berangkat ke kutha Lateng dengan dikawaloleh orangorang Madura dengan maksud untuk mengambil Wong Agung Willis. Sesampainya di tempat tinggal/dalem Pangeran Willis., didapatinya Pangeran Willis sedang sakit. Beliau telah menyuruh untuk mengusung keluar di atas pembaringan.kemudian beliau berkata, bahwa beliau sanggup, akan segera datang ke benteng Banyualit, bila kesehatanya telah pulih kembali. Melihat kejadian itu, A. Van Rijke kemudian tidak mengherankan kedua orang pengawal (kapten laut) yang mengiringi A. Van Rijke. Penvira Madura yaitu Kapten Sirna Antakayang menyertainya, sebenamya ingin memaksa beliau secara kekuasaan.

Keesokan harinya, 02 Maret 1768 Adrianus Van Rijke menerima khabar bahwa bupati Blambangan Ki Mas Bagus Anom dan Mas Uno/Weka telah menghianati VOC. Mereka ini telah besumpah setia pada Pangeran Wilis. Ketika itu perlawanan telah berkobar secara mendadak. Kota Ulupangpang menjadi pusat pembrontakan para pengikut Pangeran Wilis. Dalam beberapa hari saja, Adrianus Van Rijke telah terkepung oleh musuhnya dalam beteng Banyualit, (C. Lekkerker ,1923: 1053).

\section{Perlawanan Rakyat Blambangan yang Dipimpin Rempeg Jagapati \\ Perang Bayu ini ternyata berlangsung} 2 kali yang Pertama berlangsung tahun 1771, sedang kedua 1772. pada tempat yang sama. Perang Bayu adalah perang rakyat Blambangan yang didukung kuat oleh rakyat dan negara Bali melawan Belanda dengan lembaga VOC-nya yang dengan memperalat/memaksa rakyat Madura dan Mataram atau orang Asia lainnya membela kepentingan VOC Belanda.

Tentang nama peperangan antara kedua belah pihak Satu versi menyebut bahwa peperangan itu dengan nnama perang Bayu dalam arti perang habishabisan, karena dalam bahasa asing puputan; artinya habis (Hasan Ali, 1995:1). Pendapat ini kernudian dilansir oleh Tibunius Catur Wibawa dalam judul skripsi UNEJ-nya, Bayu 1771-1772 suatu kajian tentang perlawanan rakyat Blambangan terhadap, VOC, Maret 1996. Menurut Nyoman S. Pendit, perang puputan adalah poroisi perang habisan dimana pemimpin beserta seluruh anak buahnya ikut tewas bersama sama karena tidak sudi bertekuk lutut di depan musuh (1979:147 juga dalam T. Catur 
Wibawa, 1996:4). Puputan adalah perang habis-habisan yang sering dilakukan oleh masyarakat Bali sebagai satu-satunya jalan yang ditempuh dalam usaha mengenyahkan Kolonialisme Belanda ( Nasional Indonesia, Cipta Adi Pusaka, 1990:457) juga dalam (Wibawa, 1996:4).

Atas dasar pendapat itulah maka dilain pihak tidak setuju bilamana perang rakyat Blambangan dengan VOC itu disebut PerangPuputan Bayu, karena masih ratusan orang Blambangan di Bayu lebih baik menyerah kalah dan menjadi tawanan perang Belanda daripada melawan hingga puput mati karena posisinya telah tidak memungkinkan untuk melawan Sedang ratusan yang lain memutuskan untuk masuk hutan, salah seorang pemimpin elitnya yaitu Bapa Enda memilih menyingkir ke Nusa barung, selatan Puger untuk melanjutkan perlawanan terhadap VOC.

Kedudukan Belanda yang kuat itu, kemudian membentuk pemerintahan baru di Blambangan dengan Bupati Jaksanagara, bekas Patih Wangsengsari, satu-satunya orang yang masih setia kepada Kompeni. Tetapi, Pengangkatan Jaksanagara ini tidak disukai oleh Gubernur Vos yang menginginkan bupati di Blambangan harus orang yang cakap dan berpengalaman. Blambangan yang merupakan daerah korflik, memerlukan bupati yang mampu mengendalikan rakyat. Maka, ditunjuklah Kertawijaya dari Surabaya sebagai bupati di Blambangan. Namun, tidak lama kemudian mucullah pergolakan, karena rakyat Blambangan bersikap keras untuk tidak menerima seorang Jawa sebagai bupatinya. Setelah kejadian itu, Jaksanagara tetap menjadi bupati tunggal di Blambangan. Ternyata, pengangkatan Jaksanagara inipun tidak memuaskan rakyat. Rakyat tidak menyukai seorang pemimpin yang takluk dan tunduk kepada Kompeni. Rakyat menuntut agar Sutanagara yang sernula dibuang ke Cey1on dipulangkan kembali. (Lekkerkerker, 1932:1055)

Pasukan Mas Rempeg menyadari bahwa kekuatan senjata yang masih terbatas, hanya mempunyai senjata yang sedikit, yakni tombak, lembing, keris serta pedang, sedangkan senapan dan meriarn yang dibanggakan waktu itu jatuh ditangan V.O.C. ketika berperang di Ulupampang, Banyualit, dan Lateng. Sementara itu, orang Cina dan Bugis yang semula bersedia rnemberikan senjata

kepada pasukan Mas Rernpeg juga sudah ditangkap paska waktu Ulupampang jatuh ke tangan pasukan Belanda. Untuk memberikan dukungan moral dan kepercayaan rakyat, Mas Rempeg mengatakan kepada pengikutnya, bahwa Gusti Allah akan menganugerahkan meriarn kepadanya jelas, sandaran dalam bentuk kepereayaan agama sangat penting dan dimanfaatkan dengan efektif oleh Mas Rempeg pada saat-saat yang sangat genting dalam peperangan.

Akibat pengaruh Mas Rempeg tersebut, dukungan massa tidak hanya datang dari rakvat kecil, namun juga datang dari para bekel agung, yaitu pembantu regen yang berkedudukan di Kutha Lateng, seperti Wiramanggala, Jagakrasa, serta Lembu Giri dari Tornogorn selain menyatakan bergabung dengan Mas Rempeg juga memberikan sejumlah senjata. Datang juga serombongan orang-orang Lateng di bawah pimpinan lurah Manowadi dan Bapa Cele dari Grajagan di Pesisir Selatan.

\section{Akhir Perlawanan Rakyat Blambangan}

Sejak berakhirnya Perang Wilis pada 18 Mei 1768, pemerintah VOC Belanda di Blambangan mulai menyusun kembali pemerintahannya. Pada akhir perang banyak para bangsawan keturunan Wong Agung Wilis tetap meneruskan perjuangan mengusir kaum penjajah. Sekalipun perlawanan Wong Agung Wilis tidak berhasil mengalahkan pasukan VOC di Blambanga, namun, semangat juang dan kepemimpinanya yang begitu kharismatik telah mengilhami para pejuang tetap melawan keberadaan Belanda di Blambangan.

Meskipun dalam perjuangan melawan Belanda di Blambangan Wong Agung Wilis berhasil ditangkap, diasingkan, dan akhirnya meninggal dunia, tetapi pengaruhnya sangat 
besar sekali bagi rakyat Blambangan. Nilainilai kepahlawanan Wong Agung Wilis tetap berakar di kalangan masyarakatnya sehingga jika muncul para tokoh pejuang baru, mereka dianggap sebagai jelmaan atau reenkarnasi Wong Agung (Basri, 2006:88.) Akibat Perang Wilis adalah banyaknya pelarian pejuang Blambangan yang mengungsi menuju ke Pulau Bali, memaksa gubernur VOC di Jawa, di Kota Semarang, yaitu Johannes Vos mengirim surat pada raja Bali tertanggal 14 Oktober 1768. Isi surat tersebut intinya memberitahukan bahwa semua pelarian orang Blambangan akibat perang dianggap sebagai orang-orang pelarian. (Samsubur, 2006:159)

Selain pelarian sisa-sisa pasukan Wilis ke Bali, para tawanan perang yang tertangkap oleh Kumpeni Belanda di buang ke berbagai daerah jajahan Belanda. Beberapa etnis Cina di kembalikan ke tanah leluhurnya. Para wanita pembantu sebagian dari kerabat keraton sebanyak 12 orang termasuk isteri Mas Bagus Anom dipenjara di Pulau Onrust, dekat Teluk Jakarta.

Akibat yang lain dari perang Wilis membuat pemerintah Kumpeni Belanda di Blambangan menjadi bingung apa yang harus dikerjakan terlebih dahulu dalam menata pemerintahan. Hal ini dinyatakan oleh Petrus Albeltrus van der Parra, gubernur jenderal VOC di Nusantara kepada Pangeran Orange di Nederland tertanggal Batavia, 31 Desember 1768. Isi surat tersebut antara lain berbunyi: "pekerjaan apa yang telah dilakukan di Blambangan dan apa yang harus dikerjakan, untuk terwujudnya ketenangan dan situasi yang menguntungkan perusahaan?. Kami belum mengetahui semuanya. Kami masih menunda sesuai dengan keadaanya. (Jonge, 1883:88)

Rasa kebingungan apa yang harus dilakukan oleh pemerintah Kumpeni Belanda di Blambangan nampak pada waktu menyusun dan mengatur pemerintahannya dengan menempatkan pasukan VOC hanya 74 serdadu untuk seluruh wilayah Blambangan Barat. Pasukan yang relatif kecil itu masih terbagi atas daerah
Ulupampang sebagai pusat perdagangan Kutha-Lateng (Ragajampi), dan di Banyualit. Kemudian 21 serdadu di tempatkan di Lumajang, 14 pasukan untuk Malang, 29 serdadu ditempatkan di Ngantang.

Selama Perang Wilis yang dimulai sejak 21 Maret 1767 dan berakhir pada tanggal 18 Mei 1768, serdadu Belanda banyak yang gugur disamping dipicu oleh wabah penyakit kolera tercacat 355 serdadu meninggal akibat penyakit tersebut. Akibat perang, mendorong pemerintah VOC yang pada masa itu dipimpin oleh Mayor Colmond, melakukan tindakan keras terhadap rakyat Blambangan. la menuntut penyerahan sebagian besar hasil panen untuk keperluan serdadu VOC. Apabila mereka menolak atau penarikan padi itu tidak terangkut oleh VOC, mereka harus memilih untuk dibakar atau dimusnahkan. Rakyat Blambangan dipaksa kerja rodi tanpa diberi imbalan untuk memelihara tempattempat pasukan VOC. Pekerjaan rodi inipun bahkan tidak diberi makan sama sekali. Pasukan VOC memperketat penjaaan pantai untuk menjaga kemungkinan terjadinya pergolakan rakyat Bali.

Sehabis perang, pemerintah Belanda lebih memperkokoh posisi kedua bupati Blambangan, yakni Mas Sutanegara dan Mas Wasengsari. Penempatan "sistem bupati kembar" dengan cara memecah wilayah Blambangan Barat dan Timur merupakan taktik dan strategi VOC untuk memecah belah perjuangan rakyat Blambangan.

Kedua penguasa itu dipaksa untuk memeluk agama Islam dalam upaya menjauhkan keterdekatan dengan rakyatnya. Bagi VOC hal itu memiliki nilai-nilai politis. Sebenarnya bukan merupakan persyaratan pokok untuk menduduki jabatan bupati, seorang penguasa harus memeluk agama Islam.

Akibat lebih jauh dari Perang Wilis, VOC kurang memaksakan islamisai; meskipun demikian agama Hindu dengan cepat kehilangan landasan di Ujung Timur. Hal inilah sebenarnya merupakan keunikan sejarah VOC bahwa di Ujung Timur, dimana mereka menghadapi ancaman campur tangan orang-orang Bali yang memeluk 
DOI:

agama Hindu, VOC justru membantu penyebaran agama Islam yang sangat ditakutinya di tempat-tempat lain di Indonesia. (Hardjowidjono, 1995:153)

Penghianatan yang dilakukan oleh Mas Weka, menyebabkan Wong Agung Wilis berhasil ditangkap oleh pasukan VOC di Dusun Blimbingsari, terletak antara Banyualit dan Kutha-Lateng, setelah ia menyingkir dalam pertempuran di Kutha-Lateng. Maksud Mas Weka menujukkan tempat persembunyian Wong Agung Wilis di Dusun Blimbingsari agar ia dapat diampuni kesalahan-kesalahan yang telah dilakukan dan juga masih adanya keinginan menduduki jabatan sebagai penguasa di Blambangan. Namun, VOC tidak mempercayai sepenuhnya terhadap Mas Weka. Di mata pengikut Wong Agung Wilis menilai bahwa Mas Weka yang telah menunjukkan tempat persembunyian pemimpinnya merupakan pengkhianatan besar. Informasi bahwa Mas Weka sebagai kaki tangan Belanda datang dari Mas Ularan sebagai penasehat dan matamata Pangeran Wilis. Seperti diketahui bahwa Mas Weka adalah masih saudara Mas Ularan.

\section{PEMBAHASAN}

Berdasarkan hasil dari pembahasan, maka dalam penelitian ini dapat ditarik kesimpulan bahwa: Perlawanan rakyat Blambangan adalah perlawanan untuk mengusir VOC Belanda yang ingin menguasai daerah kerajaan Blambangan peristiwa perlawanan rakyat Blambangan yang dipimpin oleh Wong Agung Willis dan

Rempeg Jagapati adalah wujud peperangan melawan pihak penjajah Belanda di Blambangan.

Wong Agung Willis merupakan simbol perlawanan menentang kehadiran belanda yang diyakini sebagai pihak penjajah. Simbol yang merupakan tanda pengenal dalam wujud Wong Agung Willis tetap merupakan sasaran, menjadi objek dalam tindakan untuk berperan. Sasaran yang dituju dalam perang itu adalah bercokolnya Kumpeni Belanda di Blambangan.
Dalam wujud peperangan yang dipimpin oleh Wong Agung Willis beserta para punggawanya melawan Kumpeni Belanda, merupakan dasar kekerasan yang langsung menyerang secara fisik terhadap keberadaan kaum penjajah. Tujuan peperangan tidak lain ingin mengakhiri penjajahan dan rakyat Blambangan menginginkan adanya kebebasan dari penindasan atau penjajahan.

Selain Perlawanan yang dipimpin oleh Wong Agung willis muncul penerusnya yaitu Rempeg Jagapati, meskipun pada akhir perlawananya Pangeran Jagapati wafat, ia gugur dalam medan Perang Bayu 1771 di Bayu, Blambangan. Semasa hidup ia telah berjuang demi tanah Blambangan menentang penjajahan Belanda di Wilayahnya. Dalam keadaan luka-luka yang diderita akibat perang, ia masih sempat memberikan komando kepada para pengikutnya untuk meneruskan perjuangan melawan kolonialisme Belanda di Blambangan.

Sekalipun pangeran Jagapati telah tiada, namanya tetap abadi dalam hati rakyat Banyuwangi. Namanya telah diabadikan dalam nama perkumpulan, nama gedung fasilitas umum, nama jalan, nama lembaga dan lain - lain. Kemenangan Pangeran Jagapati dalam Perang Bayu tanggal 18 Desember 1771 melawan pasukan- pasukan VOC, tanggal kemenangan tersebut telah diperingati untuk dijadikan sebagai sejarah hari jadi Banyuwangi.Pangeran jagapati sebagai tokoh pahlawan perjuangan kemerdekaan Blambangan, diharapkan dapat membangkitkan semangat kepahlawanan, menanamkan nilai-nilai patriotisme dan nasionalisme rakyat Banyuwangi. Pangeran jagapti telah mencurahkan tenaga dan pikiranya serta seluruh hidupnya bagi kejayaan bangsa dan negara. Perjuangan pangeran jagapati dapat menjadi suri teladan dan panutan bagi warga Banyuwangi pada masa kini dan masa depan.

Perjuangan pangeran jagapati yang telah didukung oleh seluruh rakyat Blambangan menentang kolonialisme Belanda bukanlah suatu angan - angan belaka, tetapi hal ini merupakan suatu 
kenyataan. Sejarah telah mencatat, menjadi saksi, bahwa ia beserta para pejuang lainya telah mengorbankan jiwa dan raga serta harta bendaya untuk menegakkan kemerdekaaan bangsa dan tanah air yang dicintainya. Makna yang terkandung dalam perlawanan mengusir penjajah Belanda, menunjukan betapa besar nilai-nilai perjuangan yang dilakukan oleh Pangeran Jagapati beserta para pengikutnya.

Semangat juang Pangeran Jagapati tidaklah patah, sekalipun ia telah tiada, bahkan sebaliknya semangat itu makin menyala. Sulit bagi penjajah belanda untuk mengukur betapa besar peran para pejuang Blambangan yang dipimpin Pangeran Jagapati. Semangat juang Pangeran Jagapati terilhami oleh perjuangan Wong Agung Wilis, yang dikatakan bahwa rohnya telah menitis kepada Pangeran Jagapati.

Para pengikut Jagapati seperti Sayu Wiwit, Bapa Endha, Bapa Larat, dan sejumlah pejuang yang lain, telah melanjutkan perjuanganya dalam bentuk pemberontakan- pemberontakan lokal di berbagai daerah.

Sepuluh tahun usai Perang Bayu, berbagai pemberontakan terjadi di daerah Gendoh yang dipimpin oleh Hanggapati, Ki Mas Aceh, dan pemberontakan yang dipimpin oleh pangeran Singo pada tahun 1781. Pengaruh Perang Bayu begitu bergelora menyemangati pemberontakan lokal Blambangan.

Nilai-nilai patriotisme dan nasionalisme yang diwariskan oleh pejuangpejuang pangeran Jagapati untuk mengusir kaum penjajah tidak dilakukan melalui perundingan damai, tetapi harus ditempuh melalui perang Bayu yang bagi pemerintah kolonial Belanda sangat banyak menderita kerugian baik yang menyangkut harta benda maupun nyawa. Perjuangan Pangeran Jagapati di Blambangan sejajar dengan berbagai perjuangan yang dilakukan para pejuang yang lain di berbagai wilayah di indonesia.

\section{KESIMPULAN}

Berdasarkan uraian di atas, sebutan "Indonesia Utara" yang dicetuskan oleh Tan Malaka terhadap negara Filipina tidak lepas dari pengalaman pribadinya saat menjadi orang pelarian di negeri itu, di mana ia sempat memperoleh simpati dari sejumlah orang hingga tokoh penting seperti Emilio Aguinaldo. Namun selain karena pengalaman pribadinya, Tan Malaka sebagai seorang intelektual dan aktivis Kiri, tentu mempunyai landasan literal ilmiah yang tergambar dalam tiga aspek utama pembentuk gagasannya tersebut. Pertama, dari sisi linguistik, bahasa Tagalog memiliki kemiripan dengan bahasa Indonesia serta bahasa-bahasa daerah lainnya di Indonesia karena masih tergolong rumpun Austronesia (Melayu-Polinesia). Kedua, kesamaan bentuk fisik orang-orang Filipina dan Indonesia yang tergolong dalam sub-ras Malayid yang telah menyebar di sebagian besar kawasan Asia Tenggara, utamanya di kawasan rantau Melayu. Ketiga, hubungan sejarah antara Indonesia dan Filipina terutama di era penyebaran hegemoni Majapahit yang dibuktikan dengan adanya pengaruh budaya dalam bentuk pakaian maupun senjata tradisional. Akan tetapi masih tergambar distorsi pemikiran Tan Malaka tatkala menyebut nenek moyang bangsa Filipina sebagai "The First Indonesian", ataupun observasinya tentang percampuran ras antara penduduk asli Filipina dengan orang Cina yang terbatas pada kelas borjuis.

\section{DAFTAR PUSTAKA}

Abdurahman, D. (1999). Metode Penelitian Sejarah. Jakarta: Logos Wacana IImu.

Arifin, E. B. (2008). Wong Agung Willis Pahlawan Blambangan (17671780). Banyuwangi: Dinas Kebudayaan Dan Pariwisata Kabupaten Banyuwangi.

Basri, H (Ed.). (2006). Pangeran Jagapati, Wong Agung Willis, Sayu Wiwit. Tiga Pejuang Dari Blambangan. Banyuwangi: Penerbit Pemerintah Daerah Kabupaten Banyuwangi.

Boxer, C. (1983). Jan Kompeni: Sejarah VOC dalam Perang dan Damai 1602-1799. Jakarta: Sinar Harapan. Gottschalk, L. (1986). Mengerti Sejarah. Jakarta: UI Press. 
Ismaun. (2005). Sejarah Sebagai IImu. Jakarta: Historia Utama Press. Jonge, J. D. (1883). De Opkomst Van Het Nederlandsch. ML van De Venter.

Kartodirdjo, S. (1987). Pengantar Sejarah Indonesia. Jakarta: Gramedia.

Lekkerkerker, C. (1923). Blambangan, Indisvhe Gides II. Margana, S. (2012). Ujung Timur

Jawa, 1763-1813: Perebutan Hegemoni Blambangan. Yogyakarta: Pustaka Ifada.

Samsubur. (2011). Sejarah Kerajaan Blambangan. Surabaya: Paramita Publisher.

Scott, J. C.(1981). Moral ekonomi Petani, Pergola kan dan Subsistensi di AsiaTenggara , LP3ES, Jakarta.
Sjamsuddin, H. (2007). Metodologi Sejarah. Proyek Pendidikan Tenaga Akademik: Jakarta.

Soetrisno. 1976. Metodologi Research. Yayasan Penerbit Fakultas Psikologi UGM.

Winarsih, P.A. (1995). Babad Blambangan. Yogyakarta: Bentang.

Wibawa, T. Catur. (Maret 1996).

Perang Puputan Bayu Tahun 1771-1772, Tentang Perlawanan Rakyat Blambangan Terhadap V.O.C. Universitas Jember.

Zed, Mestika, 2008, Metode Penelitian Kepustakaan, Jakarta : Yayasan Obor Indonesia. 